\section{Rana ulukalensis Nakatani, 1969, A Junior Synonym of Rana tweediei Smith, 1935 (Amphibia: Anura: Dicroglossidae)}

\author{
INDRANEIL DAS
}

\section{Institute of Biodiversity and Environmental Conservation, Universiti Malaysia Sarawak, 94300 Kota Samarahan, Sarawak, MALAYSIA}

\begin{abstract}
The nomen Rana ulukalensis, occupied by Nakatani (1969) for a frog collected from the foot of "Mount Ulu Kali", situated at the headwaters of Batang Kali, a river NNE of Kuala Lumpur, Malaysia, is shown to be a subjective junior synonym of Rana tweediei Smith, 1935, whose currently valid name is Limnonectes tweediei (Smith, 1935).
\end{abstract}

Key words: Rana ulukalensis, Limnonectes tweediei, synonymy, Malaysia

The zoological nomen, Rana ulukalensis appears in the Japanese title of a paper published by Nakatani (1969), for a possibly new species of frog, represented by a single specimen, collected from the foot of "Mount Ulu Kali" (=Gunung Hulu or Ulu Kali), situated at the headwaters of Batang Kali, a river NNE of Kuala Lumpur, Malaysia. The rugged landscape of the region is popularly referred to as the Genting Highlands, and owing to its proximity to the national capital, is a relatively well-collected area (see Bedawi et al., 2009). Sampling elevation and geographical coordinates were not supplied, although the summit of Gunung Kali is located at $03.433 \mathrm{~N}$, 101.783E, 1,720m asl (Barrientos, 2009). No further use of the name can be found in the body of the paper, although the same specimen is referred to as Rana ulikalensis subsequently (p. 11). The paper also includes a

E-mail address: idas@ibec.unimas.my short description (in English) and a description (in Japanese) of the new species, and line drawings arranged in two plates. Possibly as a result of the overlook, Rana ulukalensis Nakatani, 1969 is unlisted in the next review of the amphibians of Peninsular Malaysia, that of Berry (1975) and in contemporary databases of the world's amphibian names (Frost, 2009; AmphibiaWeb, 2009). Nonetheless, Nakatani's (1969) new name was validly published, as only descriptions of taxa of the species-group published after 1999 should contain the fixation of name-bearing types, in agreement with Article 16.4 of the Code (International Commission of Zoological Nomenclature, 1999).

As the name of the species has been presented in two orthographies, the selection of one as valid is desirable. Article 24.2.3 of the International Code of Zoological Nomenclature (International Commission of Zoological Nomenclature, 1999, hereafter, The Code) mentions that in such a case, the first author to cite them together can select one spelling as correct (=the First Reviser Principle), which would render the alternate original spelling as incorrect, and therefore nomenclaturally unavailable. Since no such selection has ever been made, in accordance with Article 24.2.3 and Recommendation 24a of The Code, which states that the selection should be the one that "best serves stability and universality of nomenclature," I select, as First Reviser, the nomen Rana ulukalensis Nakatani, 1969 as valid for the taxon, instead of Rana ulikalensis Nakatani, 1969. The spelling Rana ulikalensis with this action and in conformance with that Article, has no nomenclatural status.

The purported new Malaysian frog was compared with five species of the genus Rana (sensu lato), including those from Europe, and southeastern and eastern Asia. Although a specimen was reportedly collected, there is no explicit designation of a holotype or mention of its deposition in an institutional collection. The use of ' $n$. sp.', however, in the title makes the author's intentions clear. The short description and seven text figures pro- 